\title{
Finite Element and Experimental Vibration Analysis of High-Pressure Fuel Injection Pipe for 8-Cylinder V Diesel Engine
}

\author{
D.O.I - 10.51201/Jusst12676
}

http://doi.org/10.51201/Jusst12676

\author{
Chetan Patil $^{1 *}$, Rajesh Askhedkar ${ }^{2}$, Ratnakar Ghorpade $^{1}$, Amit Jomde $^{1}$ \\ ${ }^{1}$ School of Mechanical Engineering, MIT World Peace University, Pune, India. \\ ${ }^{2}$ Kirloskar Oil Engine Ltd., Pune, India.
}

\begin{abstract}
Designing of fuel injection pipe for high fuel pressure and vibrations is most important for a diesel engine's safety and performance. The failure of the fuel injection pipe of a Diesel engine is critical when running at full load condition. This paper presents the mode shapes, natural frequencies, and harmonic analysis of fuel injection pipes to identify the cause of failure. Finite element analysis is conducted to study dynamic behavior under a range of excitation frequencies. In these natural frequencies and mode shapes about the fuel, injection pipe is presented for different configurations. The methodology is prepared to avoid pipe failure by providing clamps at a proper location following modal parameters and providing sufficient damping in a fuel injection pipe assembly. Results indicate that excessive vibration amplitudes and incorrect clamp's location are responsible for failure (cracks in fuel injection pipes at the diesel engine's injector side). Different fuel injection pipe assemblies are discussed, control strategies and experimental results are presented to reduce vibration amplitude and stress. The existing fuel injection pipe assembly's overall vibration amplitude is reduced to $34.5 \%$ and stress by $75 \%$ through the modified assembly.
\end{abstract}

Keywords: Fuel injection pipe, Vibration fatigue, Modal analysis, Harmonic analysis, FFT analyzer

\section{Introduction}

Fuel injection pipe is a primary and essential part of the fuel injection system. It carries a high fuel pressure up to 1800 bar from the fuel pump to the fuel injector. Increasing the efficiency and engine power by improving the high-pressure injection system is very common in diesel engines. The failure of fuel injection pipe directly affects a diesel engine's performance and hence economically not profitable. Thus, vibration analysis is the best way to get more and more information about a diesel engine without shutting them down. Designing a high-pressure fuel injection pipe for high fuel pressure and vibration coming from the engine is more and more crucial, leading to the initiation of crack and finally leads to failure at the neck portion of the pipe. In some cases, structural modification of the fuel injection pipe is needed to avoid failures.

A fatigue failure leads to the fracture of a high-pressure fuel injection pipe at the interface between the head and the pipe body. The crack initiates from the outer region and propagates inward. The resonance mainly causes the fatigue failure of the fuel injection pipe at the first-order modal frequency. The first-order modal frequency should be adjusted to avoid resonance[1][2], [3]. The cold heading improves the 
reliability of high-pressure fuel pipe. Experimental modal analysis was performed on a curved and straight pipe and presented for model validation. A data acquisition system was used to convert time response to a frequency domain, leading to the extraction of natural frequencies and mode shapes associated with the testspecimen[4][5]. The structural modifications maybe, mass modification, stiffness modification, damping modification, and tuned damper modifications useful for reducing vibration levels. The addition of cross stiffeners and an increase in the back plate thickness minimizes the vibration levels [6]. The crack initiation and propagation of the leak-off oil pipe from injection valves were driven by a fatigue mechanism facilitated by loose pipe supports (excessive pipe vibration) and corrosion pits on the pipe surface that acted as stress concentrators [4].

Generally, stresses are induced in the pipe due to the stress raisers, pulsation, and vibration due to loosening supports. A high strain is generated due to the piping shell wall resonances, complex compressor manifold vibratory modes, and piping lateral natural frequencies. The vibration mode shape usually involves lateral vibration and shell wall radial vibration. Frequency factor for calculating the mechanical natural frequencies for the classical piping configuration and various piping bend configurations presented. The relationship between piping vibration displacement, velocity, and stress is shown and criteria for judging the endurance stress limit [7]. In the hollow upsetting and heading process, the analysis of the pipe in response to the initial condition, and the impact of the deficiency on the material flow is studied [1]. The maximum value of stress induces at the fuel injection pipe's head portion. The modal analysis has been presented for fuel injection pipe to study its dynamic behaviour [8], [9].

The specifications of the engine (Kirloskar DV-08) used for the testing are mentioned in Table 1. The high-pressure fuel injection pipe is made of steel with ultimate tensile strength of $490 \mathrm{~N} \mathrm{~mm}^{-2}$ and proof strength of $355 \mathrm{~N} \mathrm{~mm}^{-2}$.

Table 1. Specifications of Kirloskar DV-08 Engine

\begin{tabular}{clcc}
\hline SN & \multicolumn{1}{c}{ Engine Model } & Unit & DV-08 \\
\hline 1 & Rated output & $\mathrm{kW}(\mathrm{hp})$ & $360(490)$ \\
2 & Frequency & $\mathrm{Hz}$ & 25 \\
3 & No. of cylinders & $\mathrm{No}$ & 8 \\
4 & Engine configuration & - & $\mathrm{V}-90^{0}$ \\
5 & Rated speed & $\mathrm{RPM}$ & 1500 \\
6 & Firing order & - & $1-5-7-2-6-3-4-8$ \\
\hline
\end{tabular}

\section{Modal analysis of fuel injection pipe}

\subsection{Finite Element Model}

The high-pressure fuel injection pipe studied is from an eightcylinder $\mathrm{V}$ type of diesel engine for a Genset. This simulation aims to carry out finite element modal analysis of the fuel injection pipe in the ANSYS workbench environment to observe the mode shapes and natural frequencies occurring at fuel injection pipe co-relation with the experimental results. The high-pressure fuel injection pipe has been meshed using 10 node tetrahedral and 20 node brick elements. 


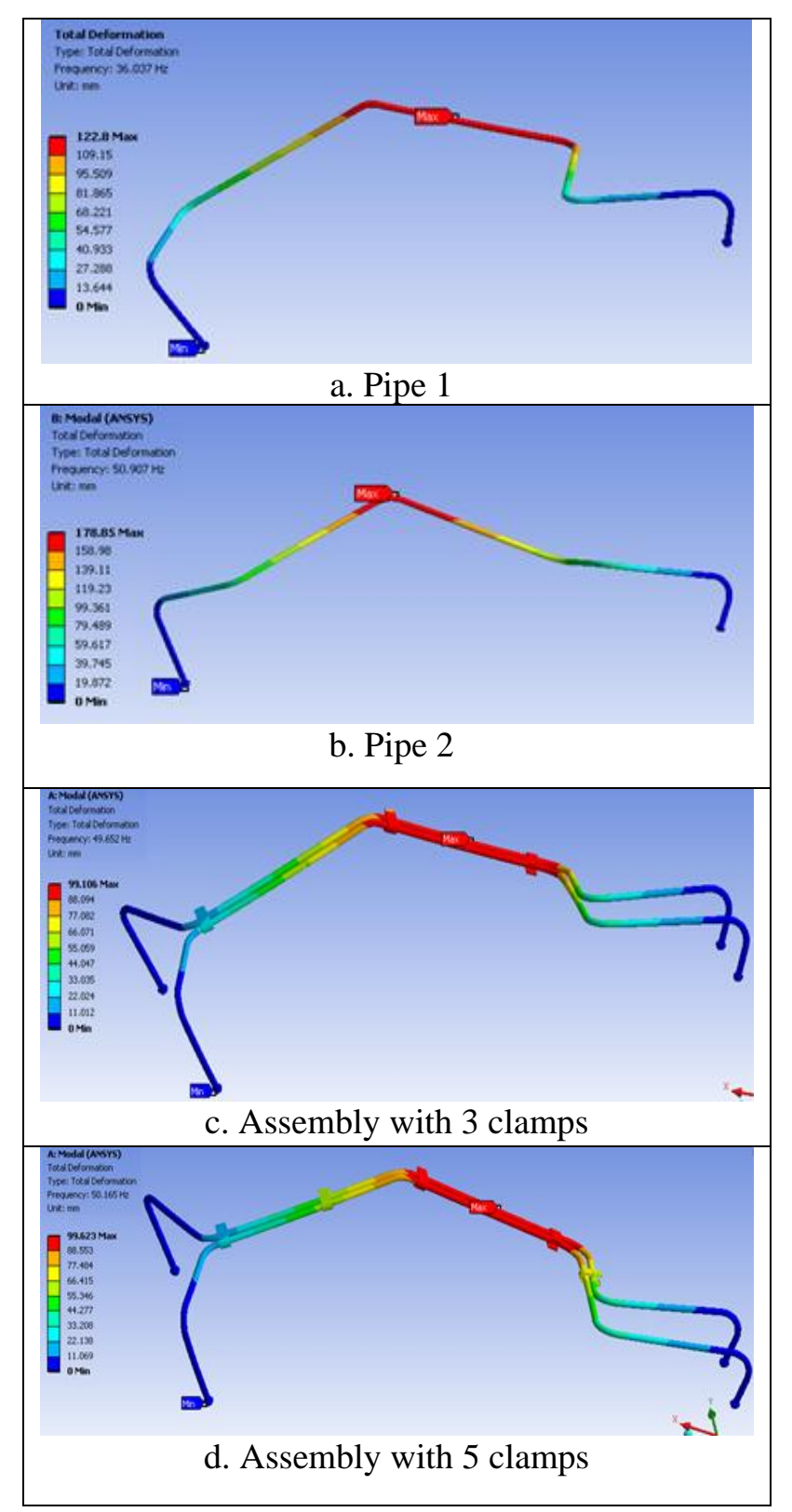

Figure 1. Modal shapes of fuel injection pipe

Figure 1shows a modal shape of fuel injection pipe for mode 1. Figure 1a shows a modal analysis of pipe number ' 1 ' for mode 1.Figure $1 \mathrm{~b}$ shows a modal analysis of pipe number ' 2 ' for mode 1 . Figure $1 \mathrm{c}$ shows a modal analysis of fuel injection pipe assembly of pipe ' 1 ' and ' 2 ' with three clamps for mode 1 . Figure $1 \mathrm{~d}$ shows the modal analysis of fuel injection pipe assembly of pipe ' 1 ' and '2' with five clamps for mode 1 . The simulation software can mesh a component with the programmable controlled method. In this method, the meshing of fuel injection pipe is carried with the auto mesh technique, and it gives more accurate results with a minimum number of nodes. Modal analysis is carried out for all assemblies up to mode shape 6 . Table 2 shows the frequencies obtained of the mentioned configuration for mode number 1. 
Table 2. Natural frequency $(\mathrm{Hz})$ of fuel pipe of Dv-08 Engine for mode 1

\begin{tabular}{cccc}
\hline High-pressure fuel pipe & No Clamp & With 3 Clamps & With 5 Clamps \\
\hline 1 & 36.03 & 49.65 & 50.16 \\
2 & 50.90 & & \\
3 & 40.18 & 75.33 & 74.59 \\
7 & 42.44 & & \\
4 & 47.18 & 67.03 & 65.69 \\
5 & 53.66 & & \\
6 & 42.59 & 69.09 & 70.17 \\
8 & 52.67 & & \\
\hline
\end{tabular}

\subsection{Modal Test}

The modal test was conducted on a fuel injection 3D bend circular pipe of a diesel engine with a specific density, strength, and dimension $(6 \times 860) \mathrm{mm}$. The assembly of the fuel injection pipe is tightened to the engine using a nut. The fuel injection pipe's modal analysis is carried out by considering fixed support at the pipe end, and no load is applied. A modal hammer applies the excitation.

For measurement purposes, a modal hammer has a frequency range of $8 \mathrm{kHz}$ (max), and the maximum is $4448 \mathrm{~N}$ used. The responses of the structure are picked up by using the uniaxial accelerometer. PULSE Labshop is used as a Fast Fourier Transform (FFT) analyzer, which receives the digital signal from the hammer and the accelerometer and converts it. FFT analyzer and accelerometer are the interface to convert the time domain response to the frequency domain. ME'scopeVES is used to display and analyze experimental multi-channel time or frequency domain data. Fuel injection pipe is modeled with the help of ME'scopeVES of 3 and 5 clamps arrangement.

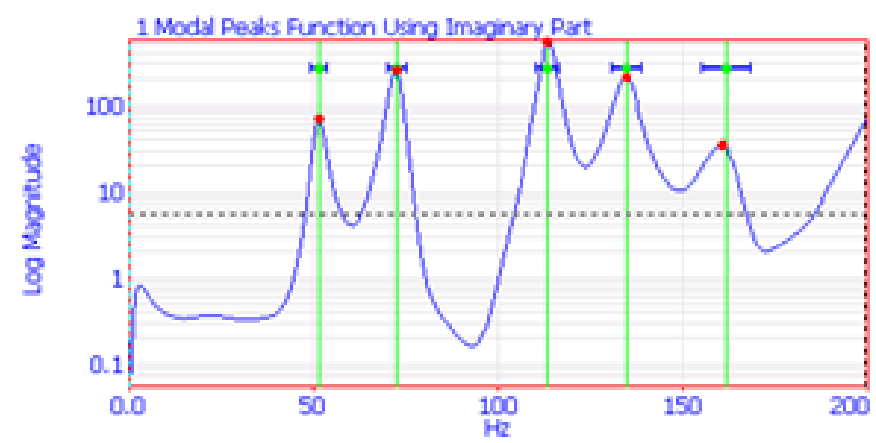

Figure 2. Frequency spectrum of fuel pipe assembly of 3 clamps

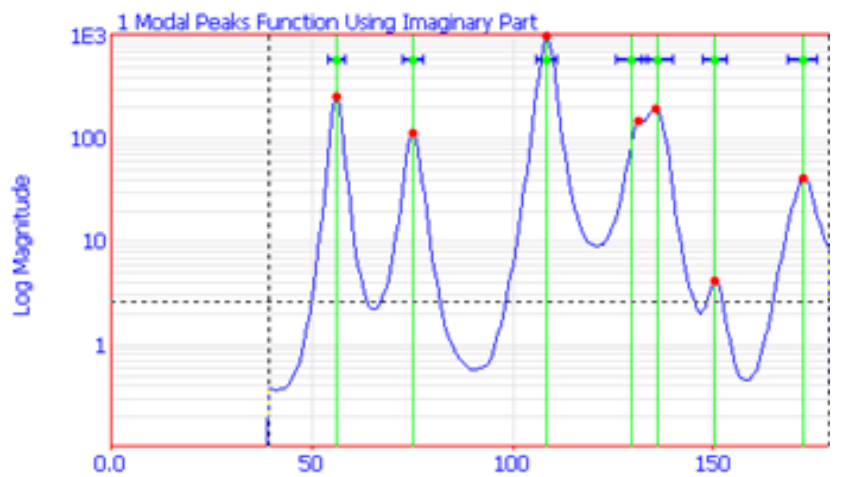

Figure 3. Frequency spectrum of fuel pipe assembly of 5 clamps 
The frequency spectrum of fuel injection pipe assembly of 3and5 clamps are shown in Figures 2 and 3, respectively. The modal frequencies obtained from the test and simulation are listed in Table 3 and Table 4, and the corresponding mode shapes are shown in Figure 1.

Table 3. Natural frequency $(\mathrm{Hz})$ of fuel pipe assembly of 3 clamps

\begin{tabular}{cccc}
\hline & \multicolumn{3}{c}{ With 3 clamp } \\
\cline { 2 - 4 } Mode no. & $\begin{array}{c}\text { Finite element } \\
\text { method }\end{array}$ & $\begin{array}{c}\text { Experimental } \\
\text { method }\end{array}$ & \% Error \\
1 & 49.65 & 51.4 & 3.3 \\
2 & 73.77 & 72.5 & 1.7 \\
3 & 110.22 & 113 & 2.4 \\
4 & 124.84 & 135 & 7.5 \\
5 & 140.07 & 162 & 13.0 \\
6 & 149.37 & 152 & 1.7 \\
\hline
\end{tabular}

Table 4. Natural frequency $(\mathrm{Hz})$ of fuel pipe assembly of 5 clamps

\begin{tabular}{cccc}
\hline Mode no. & \multicolumn{3}{c}{ With 5 clamp } \\
\cline { 2 - 4 } & $\begin{array}{c}\text { Finite element } \\
\text { method }\end{array}$ & $\begin{array}{c}\text { Experimental } \\
\text { method }\end{array}$ & \% Error \\
1 & 50.16 & 56.2 & 10.7 \\
2 & 73.84 & 75.2 & 1.8 \\
3 & 111.67 & 108 & 3.2 \\
4 & 127.4 & 130 & 2.0 \\
5 & 144.16 & 136 & 5.5 \\
6 & 150.68 & 150 & 0.4 \\
\hline
\end{tabular}

The comparison shows the relative errors between the tested and the simulation modal frequencies are within $13 \%$, and the mode shapes are consistent.

\section{Harmonic Analysis of Fuel Injection Pipe}

Generally, cyclic load produces a harmonic response in a structural system. The harmonic analysis predicts the incipient failures because of the dynamic behavior of structures. It verifies whether designs will successfully overcome fatigue and other harmful effects of forced vibrations. The experimentation was conducted for harmonic response and measured vibration amplitude of fuel injection pipe.

\subsection{Measurement of Vibration Amplitude}

A vibration test of the fuel injection pipe is carried out in operation with tri-axial accelerometers attached to the fuel pipe by glue. Vibration amplitude measured at different locations on the pipe for 3 and 5 clamps arrangement and is shown in following Figure 4. 


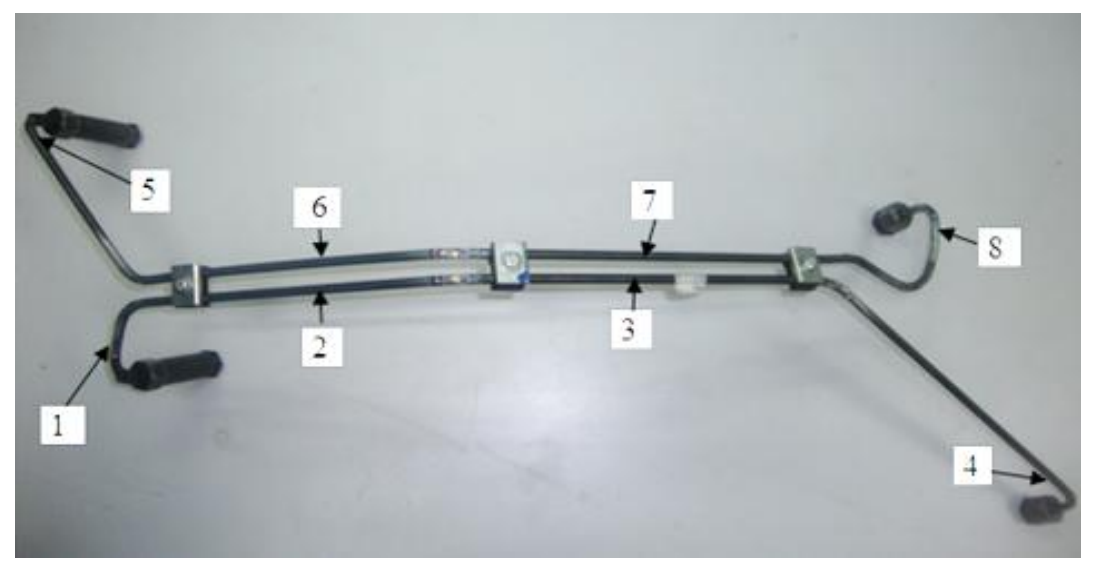

Figure 4. Location of accelerometer on fuel injection pipe

Frequency vs. displacement graph for 3 and 5 clamps arrangement at location' 1' shown in Figure 5 and 6 respectively.

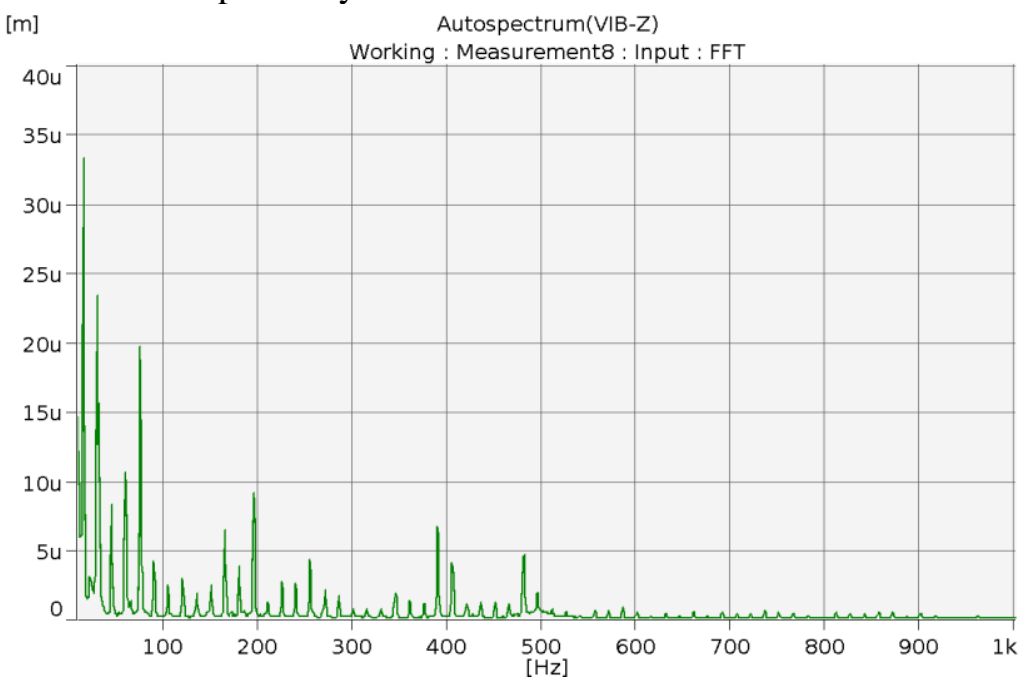

Figure 5. Frequency vs. Displacement Graph for 3 Clamps

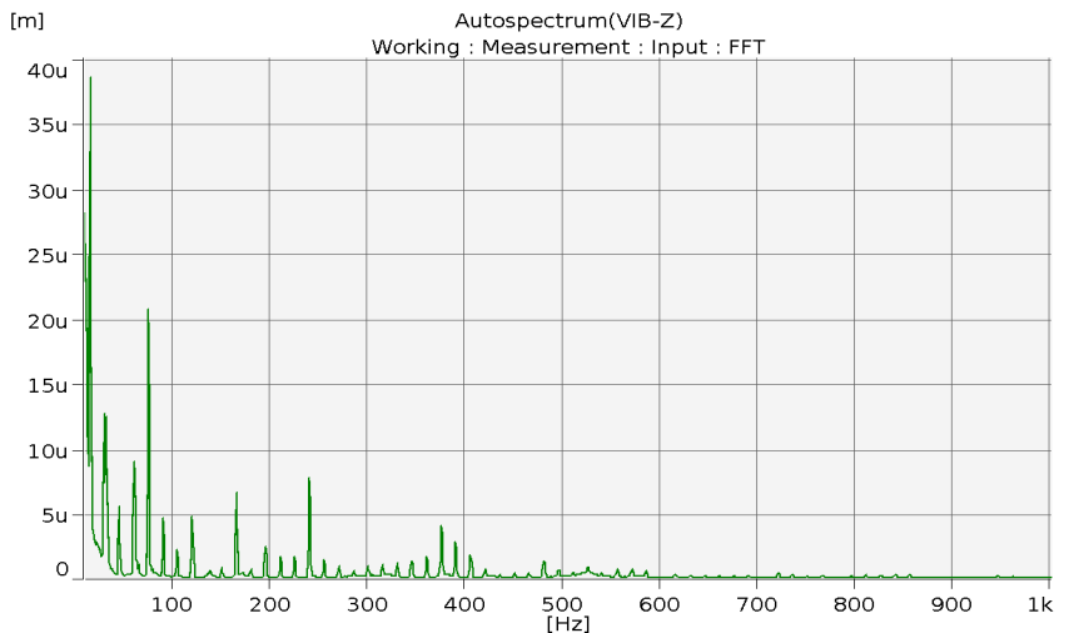

Figure 6. Frequency vs. Displacement Graph for 5 Clamps

Table 5 shows the peak to peak vibration amplitude of fuel injection pipe assembly. 
Table 5. Overall vibration levels of existing ( 3 clamps) $\&$ modified assembly (5 clamps)

\begin{tabular}{cccc}
\hline & \multicolumn{3}{c}{ 1500 RPM } \\
\cline { 2 - 4 } Location & \multicolumn{3}{c}{ Peak to Peak Vibration (mm) } \\
& 3 Clamps & 5 Clamps & \% Deviation \\
\hline 1 & 0.164 & 0.153 & 6.8 \\
2 & 0.167 & 0.173 & -3.6 \\
3 & 0.161 & 0.161 & 0 \\
4 & 0.122 & 0.115 & 5.3 \\
5 & 0.091 & 0.089 & 2.2 \\
6 & 0.164 & 0.141 & 14 \\
7 & 0.136 & 0.089 & 34.5 \\
8 & 0.231 & 0.156 & 32.4 \\
\hline
\end{tabular}

Table 5 shows that vibration amplitude is higher at the fuel pump side and the injector side for 3 clamps assembly compared with the modified 5 clamps assembly. Vibration amplitude of modified fuel injection pipe assembly is reduced up to $34.5 \%$.

\subsection{Measurement of Strain and Stress}

According to the modal analysis and the frequency response analysis, stressinduced in fuel injection pipe measured with the help of strain gauge during its full loading condition at 1500 RPM as shown in Figure7. It can be found that the stress mainly originates at the end of the fuel injection pipe body, where the fracture happens. It can be concluded that the vibration-induced stress concentration should be responsible for the fuel injection pipe failure.

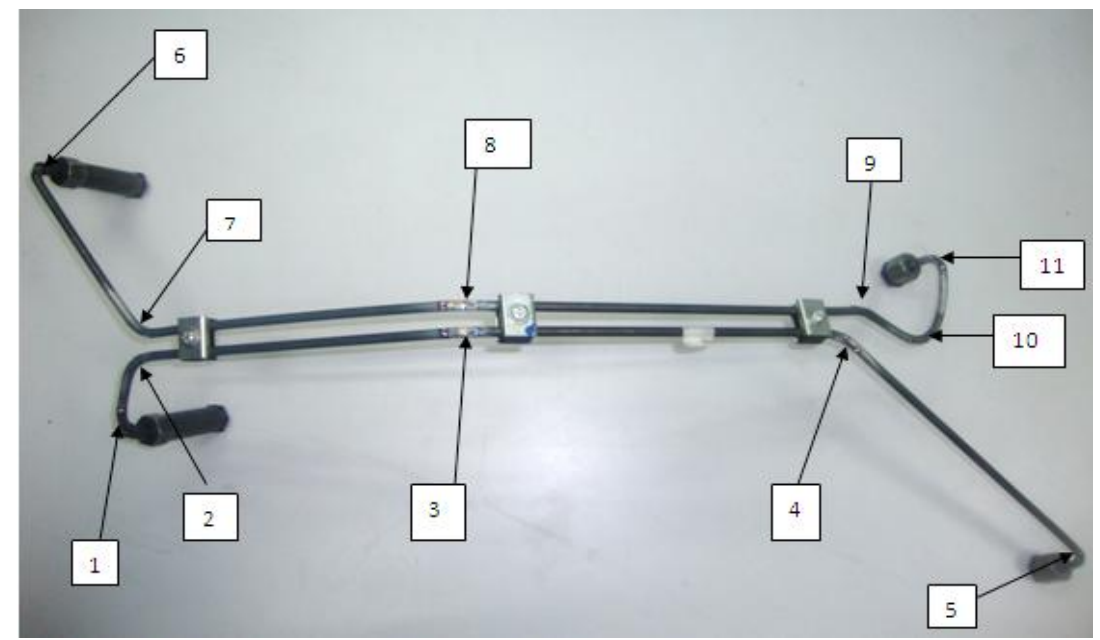

Figure 7. Locations of strain gauges on the fuel injection pipe assembly

Strain gauges are attached to the fuel injection pipe on the DV-08 Diesel engine at the critical location where the stress is measured. Strain readings were taken on different '11' locations of fuel injection pipe for three clamps and five clamps. Figure 7 shows the position of strain gauges labeled from 1 to 11 on the fuel injection pipe.

The strain gauges used are CEA06 - 62UW - 350, micro-measurements make uniaxial strain gauges, and its material is constant. A great new feature of DEWESoft is used for the measurement of strain for a particular component. The system takes input from the strain gauge that is connected to the fuel injection pipe. The strain 
gauge wire is used to connect the strain gauge and module of the DEWESoft system. Figure 8 shows the actual setup on engine for measurement of strains.

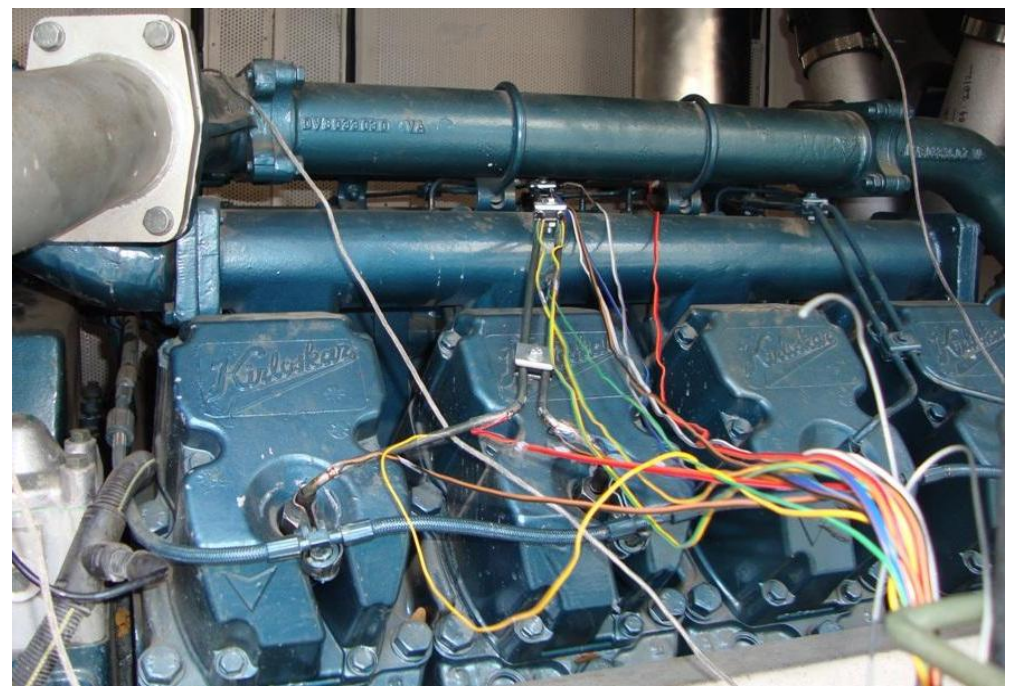

Figure 8. Actual setup on engine for measurement of strains

After the post-processing system gives the output value, i.e., strain $(\mu)$ at a particular location, generally, the data includes graphs of strain (microstrain) vs. time (sec). Figure 13 shows the strain gauge at location' 1'. Figure 9 and 10 shows the strains on existing and modified assembly. Strain readings are taken at different locations on fuel injection pipe assembly with three clamps and five clamps.

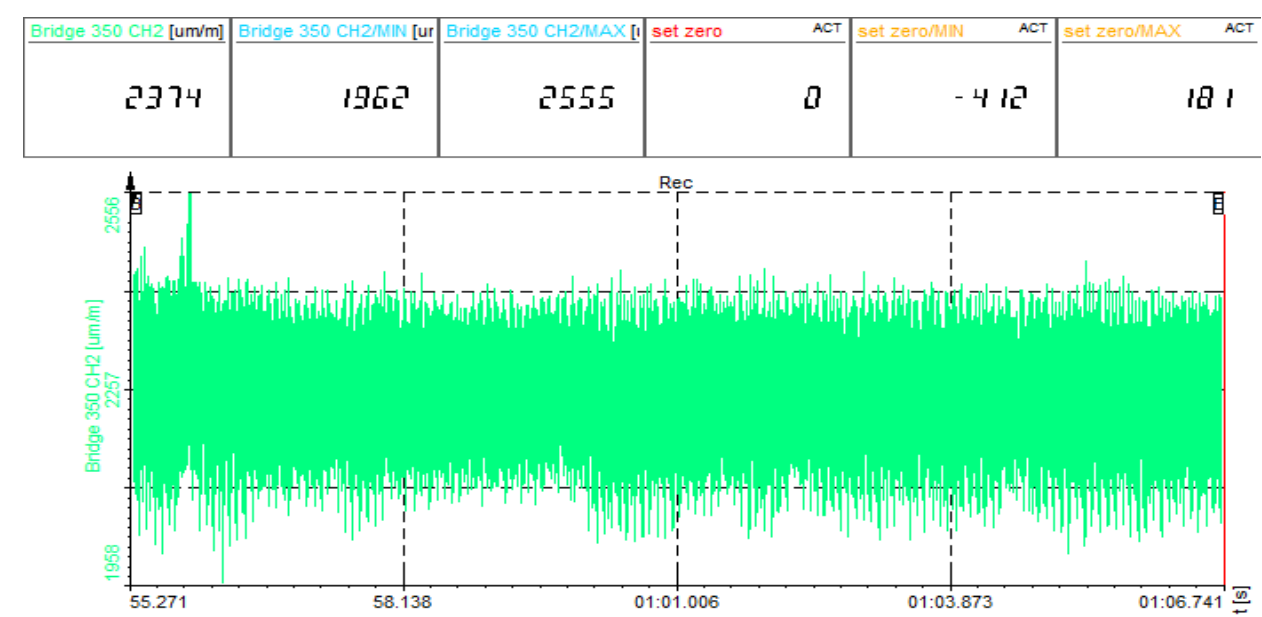

Figure 9. Strain Graph (location 1) for pipe assembly with 3 clamps 


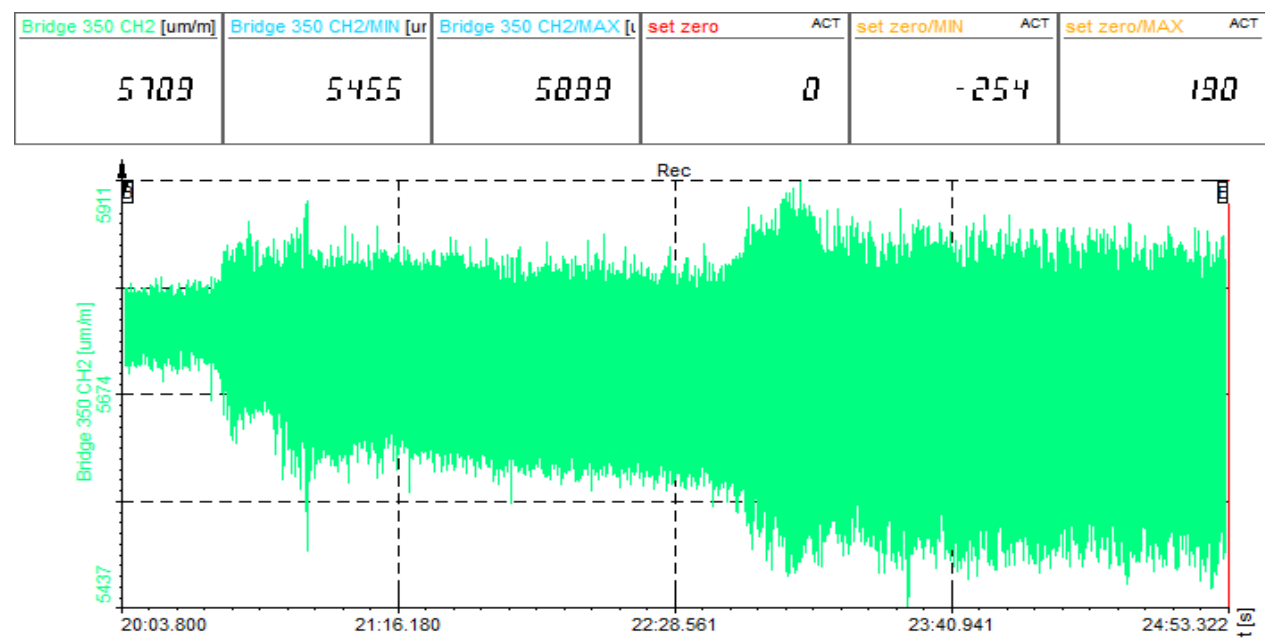

Figure 10. Strain Graph (location 1) for pipe assembly with 5 clamps

Table 6 shows that the maximum stress induced in a fuel injection pipe at location' 10 ' for three clamps arrangement is higher than the endurance limit, i.e., $98.88 \mathrm{~N}$ $\mathrm{mm}-2$. Hence, it can be concluded that the vibration-induced stress concentration should be responsible for the fuel injection pipe failure.

Table 6. Overall stress-induced in fuel injection pipe for 3 \& 5 clamps arrangement

\begin{tabular}{ccccc}
\hline \multirow{2}{*}{ Location } & \multicolumn{2}{c}{ 3 Clamp } & \multicolumn{2}{c}{ 5 Clamp } \\
\cline { 2 - 5 } & \multicolumn{3}{c}{ Stress, $\mathbf{~ m m}^{-2}$} \\
\hline & Min. & Max. & Min. & Max. \\
\hline 1 & 86.52 & 38.01 & 53.34 & 39.9 \\
2 & 34.44 & 29.19 & 19.74 & 19.32 \\
3 & 39.69 & 32.97 & 43.05 & 34.02 \\
4 & 7.35 & 64.89 & 57.96 & 36.96 \\
5 & 25.62 & 78.75 & 68.04 & 32.13 \\
6 & 12.81 & 34.86 & 38.22 & 38.22 \\
7 & 30.66 & 57.12 & 80.85 & 88.41 \\
8 & 50.61 & 33.6 & 48.72 & 34.23 \\
9 & 25.83 & 56.91 & 56.07 & 57.54 \\
10 & 179.97 & 4.83 & 43.68 & 71.82 \\
11 & 77.07 & 18.06 & 41.16 & 61.32 \\
\hline
\end{tabular}

One can avoid fuel injection pipe failure using five clamps and stress-induced at all locations within the permissible limit.

\section{Conclusions}

Modal parameter extraction and harmonic analysis for measurement of vibration amplitude and stress of high-pressure fuel injection pipe were addressed in this paper. For this study, vibration analysis of high-pressure fuel injection pipe is carried out using finite element analysis compared experimentally.

1. The experimental and FEA simulated results have deviation of $13 \%$.

2. The harmonic analysis confirms that the vibration amplitudes are the cause of failure of the fuel injection pipe.

3. The modal and harmonic analysis is a useful tool for finding out the vibration source correctly and reducing the vibration level.

4. The overall vibration amplitude of the existing fuel injection pipe assembly is 
reduced up to $34.5 \%$, and stress at the fuel pump side is significantly reduced by $75 \%$ with modified assembly.

\section{Declaration of competing interest}

The authors declared no potential conflicts of interest with respect to the research, authorship, and publication of this article.

\section{Acknowledgment}

This work was performed using facilities at Kirloskar Oil Engine Ltd., India. The authors would like to thank the staff of KOEL for the support.

\section{REFERENCES}

[1] J. H. Bae, M. S. Kim, M. J. Song, S. Y. Jung, and C. Kim, "A study on optimal design and fatigue life of the common rail pipe," Int. J. Precis. Eng. Manuf., vol. 12, no. 3, pp. 475-483, 2011.

[2] A. Jomde, A. Anderson, V. Bhojwani, P. Shinde, S. Deshmukh, and S. Phadkule, "Resonance analysis of valved linear compressor for refrigeration application," ARPN J. Eng. Appl. Sci., vol. 11, no. 23, pp. 13810-13814, 2016.

[3] S. Phadkule, S. Inamdar, A. Inamdar, A. Jomde, and V. Bhojwani, "Resonance analysis of opposed piston linear compressor for refrigerator application," International Journal of Ambient Energy, 2018.

[4] Z. Mazur, A. Carvajal-Martínez, R. Muñoz-Quezada, and R. García-Illescas, "Failure analysis of a leak-off oil pipe from injection valves of an off-shore operating diesel engine," Eng. Fail. Anal., vol. 14, no. 1, pp. 196-208, 2007.

[5] A. Jomde et al., "Modeling and simulation performance of reed valve in linear compressor," Mater. Today Proc., vol. 4, no. 8, pp. 7228-7233, 2017.

[6] D. J. Kalsule, R. R. Askhedkar, and P. R. Sajanpawar, "Engine induced vibration control for a motorcycle chassis frame by right combination of finite element method and experimental techniques," SAE Tech. Pap., no. 724, 1999.

[7] J. C. Wachel, S. J. Morton, and K. E. Atkins, "Piping Vibration Analysis," Proc. 19th Turbomach. Symp., pp. 119-134, 1990.

[8] C. Patil, R. Askhedkar, K. Group, and G. Shrigandhi, "Modal Analysis of High Pressure Fuel Injection Pipe for a DV-10 V Diesel Modal Analysis of High Pressure Fuel Injection Pipe for a DV-10 V Diesel Engine, ”vol. 04, no. July, pp. 60-64, 2020.

[9] C. M. Santana, J. E. M. Barros, and H. A. de A. Junior, "Analysis of vibration and noise of an internal combustion engine by application of test and experimental analysis of the frequency spectrum," An. do XXI Simpósio Int. Eng. Automotiva, no. February, pp. 221-245, 2014. 